UN IVERSITY OF COPENHAGEN

\title{
Other minds embodied
}

Overgaard, Søren

Published in:

Continental Philosophy Review

DOI:

10.1007/s11007-016-9388-y

Publication date:

2017

Document version

Peer reviewed version

Document license:

Unspecified

Citation for published version (APA):

Overgaard, S. (2017). Other minds embodied. Continental Philosophy Review, 50(1), 65-80.

https://doi.org/10.1007/s11007-016-9388-y 


\section{Other minds embodied}

Søren Overgaard (University of Copenhagen)

Abstract

I distinguish three kinds of other minds problems - conceptual, epistemological and empirical. I argue that while Merleau-Ponty believes embodiment helps with tackling the conceptual and epistemological problems, he suggests that it is of no clear use in solving (an important variant of) the empirical problem. I sketch some considerations that could lend support to Merleau-Ponty's claims about the conceptual and epistemological problems, without claiming that these are conclusive. I then proceed to argue that Merleau-Ponty's take on the empirical problem is essentially correct.

\section{Introduction}

Merleau-Ponty famously held that minds are embodied. As he avers repeatedly in Phenomenology of Perception, I am not just causally connected with my body, or somehow lodged inside it; rather, 'I am my body' (2012, e.g. 151, 205). Adequately grasping this point, Merleau-Ponty believes, entails rethinking a host of traditional philosophical themes, including language, the self, nature, freedom, and time, to name but a few. The notion of embodiment entails a showdown with Cartesian dualism and 'intellectualist' transcendental philosophy, and it seems to point to a 'truth of naturalism ${ }^{\text {1 }}$ while differing profoundly from the bald naturalism that Merleau-Ponty labels 'empiricism'.

My topic in this paper, however, is the impact of the notion of embodiment on the socalled problem of other minds. Merleau-Ponty claims that to the extent that I truly appreciate the 'inherence of my consciousness in its body and in its mind, the perception of others and the plurality of consciousnesses no longer present any difficulty' (366). It is natural to read this as

\footnotetext{
${ }^{1}$ I am of course alluding to the final section of The Structure of Behavior, entitled 'Is There Not a Truth of Naturalism?' (Merleau-Ponty 1963, 201). The question is answered in the affirmative in the final page of that book (ibid., 224).
} 
maintaining that if we understand minds as embodied, we do not 'solve the problem of other minds, but ... dissolve it' (Carman 2008, 135). ${ }^{2}$

I think such a reading is problematic, for several reasons. There is not one problem of other minds. Nor did Merleau-Ponty think there was. And Merleau-Ponty did not think they would all be dissolved (or solved, for that matter) if we think of minds as embodied. In this paper, I distinguish three kinds of other minds problems - conceptual, epistemological and empirical. I argue that while Merleau-Ponty believes embodiment helps with tackling the conceptual and epistemological problems, he suggests that it is of no clear use in solving an important variant of the empirical problem.

I proceed as follows. First, I distinguish between three kinds of problems of other minds. In section 3, I outline how Merleau-Ponty sees embodiment as impacting on the conceptual and the epistemological problems. In section 4 I sketch some considerations that might lend support to Merleau-Ponty's claims about the conceptual and epistemological problems, although I do not claim that these are conclusive. In section 5, I argue that Merleau-Ponty believes - correctly - that embodiment does not help to solve an important variant of the empirical problem. In section 6, I sum up the findings of the paper.

\section{Problems of Other Minds}

There are probably countless problems of other minds. Philosophical attention has, however, tended to revolve around five problems, I believe, falling into three distinct categories. Philosophers commonly distinguish between the epistemological and the conceptual problems of other minds

\footnotetext{
${ }^{2}$ As Carman reads Merleau-Ponty, the problem of other minds is one we 'ought to silence rather than answer' (Carman 2008, 136). I suspect this is true if - but only if - the problem is conceived of as a sceptical challenge. See footnote 10 below. With the exception of that short footnote, I shall not address scepticism about other minds in this paper.
} 
(e.g. Avramides 2001, 1-18; Gomes 2011; Hyslop 2010; Nagel 1986, 19; Pickard 2003). The epistemological problem is usually taken to be the problem of how we can know, or be justified in believing, that there are minds other than our own - or, as Thomas Nagel $(1986,19)$ puts it, 'how I can know that other people are not zombies' (i.e., mindless creatures that superficially resemble minded people). Call this the 'that' version of the epistemological problem. This is not the only epistemological problem that philosophers have grappled with. John Wisdom, for example, takes the epistemological problem to be the following: 'Do we know, and how do we know, the thoughts and feelings of another?' (1968, 206; cf. Austin 1979, 76). I propose to call this the 'what' version of the epistemological problem, since it does not concern our ways of knowing about the naked existence of another mind, so to speak, but rather how we can know what is on another's mind what mental state(s) another is in.

These versions of the other minds problem are obviously intimately connected, and a solution to the 'what' problem eo ipso provides a solution to the 'that' problem as well (if I can know that some other person is angry, say, then I am also in a position to know that at least one other mind exists). But, importantly, some possible solutions to the 'that' problem do little to resolve the 'what' problem. Suppose, for instance, that the best explanation for some of the things I see around me is that there are other minds about. If so, I can know by inference to best explanation that others exist. But that does not mean I can also know what those others are thinking or feeling. Perhaps they are simply incomprehensible to me - an extreme case of the sort of bewilderment one might experience in a culture very different from one's own. In the latter sort of case, there is no question that the people around one are people and thus minded. But one might have no clue what 
they are up to. Thus, this way of resolving the epistemological 'that' problem does not solve the 'what' problem. ${ }^{3}$

The conceptual problem of other minds also admits of two formulations, one in terms of the conceivability of another mind ('that' there might be other minds), and another in terms of the conceivability of mental states that aren't mine ('what' those minds might think or feel). The conceptual problem is not the problem of knowing whether there are other minds, or what their mental states might be, but the problem of how we are to understand the very notion of another mind, or of mental states not belonging to oneself. Merleau-Ponty offers a nice formulation of the conceptual problem in terms of the conceivability of other minds (or egos): 'But this is precisely the question: how can the word "I" be made plural? How can we form a general idea of the I? How can I speak of another I than my own?' (364; cf. the very similar formulations in Avramides 2001, p. 219). In The Blue Book, Wittgenstein formulates the problem in terms of particular types of mental state or episodes:

I am told: 'If you pity someone for having pains, surely you must at least believe that he has pains'. But how can I even believe this? How can these words make sense to me? How could I even have come by the idea of another's experience if there is no possibility of any evidence for it? (Wittgenstein 1958, p. 46).

\footnotetext{
${ }^{3}$ Transcendental arguments may constitute another case in point. Suppose I can know that others exist because their existence is a necessary condition for some capacity that it seems obvious that I have (see Russell and Reynolds 2011 for discussion of various arguments of this type). Even so, this may give me no justification for believing anything about the mental states of those others.
} 
The conceptual problem, regardless of the precise formulation of it, might strike one as rather silly. Whether or not we can really know what another is thinking or feeling, there is surely no problem about grasping the idea that they think or feel. Another's pain is just like my pain, only felt by another person rather than by me. So far so good. But what do I mean by 'pain'? Don't I mean this unpleasant feeling that I sometimes experience - the feeling of hurting? The idea of another's pain is the idea of this unpleasant feeling when I am not feeling it (but somebody else is). But this, someone might say, is incoherent. Because the situation we are imagining is one in which there is hurting, but in which it doesn't hurt. It seems, then, that there is something about our concept of pain that makes it difficult to see how we could apply it to another person. In some such way the conceptual problem of other minds may arise (see e.g. Pickard 2003, 89). ${ }^{4}$

Note that the problem here is not that of applying some concept of 'pain', for example, to other people. It is the problem of extending the very same concept to others that I apply in my own case. In the case of others, I apply the concept of pain on the basis of certain observable behavioural patterns (groaning, writhing, etc.). In my own case, I do so on the basis of this unpleasant inner feeling. How can it be the very same concept that I apply in both cases, when the criteria for applying it are so radically different? This is the conceptual problem of other minds (Avramides 2001, 218-230).

I said the conceptual problem admits of two formulations; I didn't say there are two versions of it. It seems obvious that a solution to the problem in its Wittgensteinian formulation equally applies to the Merleau-Pontian formulation. If I can make sense of the idea of someone else's pain then I can also make sense of the idea of another as the subject of that pain. I also suspect that if we can make sense of the idea of another mind or ego, then we can make sense of at

\footnotetext{
${ }^{4}$ I am not saying this is the most forceful compelling way for the problem to arise, nor even that the line of thought just mooted is a plausible one.
} 
least some mental states that other mind could be in. If the latter idea were utterly unintelligible to us, then I don't see how we could have a very firm grip on the notion of another mind at all. How can what we imagine be a mind if the very notion that it feels, thinks, believes or desires anything makes no sense to us? If this is right, and it seems right to me, ${ }^{5}$ then the 'what' and the 'that' formulations of the conceptual problem are really just two ways of articulating a single problem. ${ }^{6}$ In addition to the epistemological and conceptual problems, there is also what we might call the empirical problem of other minds. This is the problem of how people actually find out about other minds. What methods do people employ when they want to know what someone else is feeling or thinking? What 'subpersonal' mechanisms might be involved? Under the heading of 'theory of mind' or 'mindreading', philosophers, psychologists and others have in recent decades devoted much attention to these questions (see e.g. Goldman 2006; Nichols \& Stich 2003). In a recent article, Goldman formulates 'the core question' in the mindreading debate as follows:

How do [people], or their cognitive systems, go about the task of forming beliefs or judgments about others' mental states, states that are not directly observable?

$\left(\right.$ Goldman 2012, 402) ${ }^{7}$

\footnotetext{
${ }^{5}$ But nothing in the argument of this paper turns on these somewhat speculative remarks.

${ }^{6}$ Having said that, I take it there might be 'local' versions of the conceptual problem, attaching to particular types of mental states, problems that may persist even if the general conceptual problem has been resolved. For example, it might be that some mental states, such as sensations, pose conceptual difficulties that do not arise with respect to, say, beliefs, emotions, or desires. If so, a situation is conceivable in which we are able to make sense of the idea of another mind with beliefs and desires, say, while not being able to conceive of it as feeling pain. Perhaps our situation with respect to the notion of artificial minds is like that.

${ }^{7}$ Note that Goldman builds an assumption about mental states - namely that they are 'unobservable' - into the very formulation of the problem. The assumption is of course one that Merleau-Ponty disputes. I will return to this point later.
} 
This is the 'what' - or the 'mental state' - version of the empirical problem of other minds. The question is how people go about identifying the mental states of others, not how they go about picking out other minds - candidates for mental state attribution - in the first place. The latter would be the 'that' version of the empirical problem: How do people, or their cognitive systems, go about the task of forming the belief that something is another mind? This question has, as far as I am aware, only received a fraction of the attention lavished on the 'what' version of the empirical problem. Here I follow suit. It is the 'what' question that I want to focus on in the following.

Note that this problem is essentially different from the epistemological 'what' problem. The latter is the problem of how we can know, or be justified in believing, that another is angry, sad, and so on. But the justification that we might come up with need not reflect how we go about forming such beliefs in our daily lives. Conversely, the empirical question does concern our ordinary ways of forming beliefs of the relevant sort, regardless of whether or not the procedures we employ are any good, epistemologically speaking.

\section{Merleau-Ponty on the epistemological and conceptual problems}

Let me now turn to Merleau-Ponty. The question I want to raise in this section is whether he believes embodiment helps to solve the conceptual and epistemological problems.

I start with the conceptual problem. As we have already seen, Merleau-Ponty offers a lucid articulation of this problem in Phenomenology of Perception. And there can be little doubt that it is above all this problem Merleau-Ponty thinks dissolves once we take our embodiment into account. A few lines after formulating the conceptual problem, ${ }^{8}$ he writes: 'What we have said

\footnotetext{
${ }^{8}$ I should say that Merleau-Ponty also seems to offer a formulation of the ('that' version of) epistemological problem. Immediately after raising the question of how I can speak of another I, he writes: 'How can I know that there are other
} 
about the body provides the beginnings of a solution to this problem' (364). Indeed, two pages later, the problem seems to have disappeared altogether. I quoted part of the relevant passage in the introduction; but it is worth quoting it in full:

If I experience this inherence of my consciousness in its body and in its mind, the perception of others and the plurality of consciousnesses no longer present any difficulty. If the perceiving subject appears (to me who is reflecting upon perception) as endowed with a primordial arrangement in relation to the world, drawing with it that bodily thing without which there would be no other things for it, then why should the other bodies that I perceive not be equally inhabited by consciousnesses? If my consciousness has a body, why should other bodies not 'have' consciousness? (Merleau-Ponty 2012, 366-7)

Clearly, the point here cannot be that since my mind 'has' a body - or better: is embodied - I am thereby in a position to know that the other bodies around me are similarly embodied minds. The difficulty that is supposed to disappear here is rather a conceptual one. If I am essentially an embodied mind, then there is no fundamental obstacle to understanding how other minds could be instantiated in the bodies I see around me.

A passage in the chapter on the cogito confirms that this is indeed Merleau-Ponty's point. Again, he first provides a clear articulation of the conceptual problem of other minds, and then explains how he thinks this problem can be resolved by conceiving of minds as embodied.

I's?' (364). But when he goes on to say that the body points to the solution to the problem, he seems to have in mind the conceptual problem. For the 'essential difficulty' our embodiment helps to resolve is, he writes, 'the paradox of a consciousness seen from the outside' (364). 
How could I in the first place ever recognize other Myselves? If the subject's only experience is the one I obtain by coinciding with it, if the mind, by definition, eludes 'the outside spectator' and can only be recognized inwardly, the my Cogito is, in principle, unique - no one else could 'participate' in it. ... If I do not learn within myself to recognize the junction of the for-itself and the in-itself, then none of these mechanisms that we call 'other bodies' will ever come to life; if I have no outside, then others have no inside. $(2012,391)$

If, then, my mind is a private inner realm of experience that has no 'outside', then, according to Merleau-Ponty, it seems as if the very notion that the others around me can be minded is jettisoned. The 'others' are mere bodies: objects extended in space. The mind is radically different: it is this realm of subjective experience that I recognize within myself. The two are so different that it seems a mystery how the bodies around me in principle could be minded.

I will not pause to evaluate these claims. ${ }^{9}$ Instead, let me say a few words about how Merleau-Ponty seems to view the relation between the notion of embodiment and the two epistemological problems of other minds. ${ }^{10}$ As far as I can make out, he thinks embodiment offers an important clue to the solution to both of these problems. Consider first the 'that' version. Following Scheler (1954, 240), Merleau-Ponty claims in Phenomenology of Perception that the

\footnotetext{
${ }^{9}$ In the next section, I will suggest that embodiment might help to dispel the conceptual problem. I will, however, not assess the claim that the problem can only be dispelled in this way. For arguments in support of that claim, see Gomes 2011.

${ }^{10}$ Note that as I understand the epistemological problem here it is not primarily a sceptical challenge to our supposed knowledge of other minds. The challenge, rather, is to offer an account of how we can know about such matters (whether or not such an account would allay the sceptic's worries).
} 
notorious argument from analogy is hopeless since it 'presupposes what it is meant to explain' (p. 368). The point seems to be that for me to experience others' movements as similar to my own gestures those other movements must already be experienced as expressive of another mentality. Reasoning by analogy may be of help, Merleau-Ponty suggests, 'in the methodical knowledge [connaissance méthodique] of others and when direct perception fails, but they do not teach me about the existence of others' (p. 368). Rather, it is the fact that the other and I are both embodied, which makes the existence of the other 'evident' to me (ibid.). The suggestion seems to be that I can know that another is minded because being minded is a question of being a particular sort of (lived) body. And perception can inform me of the presence of bodies of the relevant kind.

Insofar as Merleau-Ponty here presents his embodied account as an alternative to the argument from analogy - which is standardly conceived of as addressing the epistemological problem of other minds - it is natural to think that this is also the problem Merleau-Ponty addresses. This impression is reinforced when, a few pages later, Merleau-Ponty considers what basis I might have for claiming that the other before me 'is another person, a second myself' (370). According to Merleau-Ponty, 'I primarily know [sais] this because that living body has the same structure as my own' (ibid.).

Sometimes, Merleau-Ponty also seems to touch on the 'what' version of the epistemological problem, and again he seems to suggest that embodiment is key to resolving the problem. In 'The Philosopher and His Shadow', for example, he writes:

I know [sais] unquestionably that that man over there sees, that my sensible world is also his, because I am present at his seeing, it is visible in his eyes' grasp of the scene. (Merleau-Ponty 1964a: 169) 
Eyes, here, are organs of a lived body, a body that has a world and explores that world; they are not mere material objects. And what those eyes reveal to me is not only the fact that the other sees, but also which part of the environment the other's gaze is exploring. For example, I may notice that the other's gaze 'comes to fasten on the very things that I am seeing' (ibid.). To that extent, I know not only that the other sees, but also what he or she is seeing. ${ }^{11}$

\section{Epistemology, Concepts and Embodiment}

I have suggested that Merleau-Ponty thinks embodiment is crucial when it comes to the conceptual and epistemological problems of other minds. In this section, I will sketch some considerations that might be offered in support of these views. I start with a very brief treatment of the conceptual problem.

Recall that the conceptual problem is a problem about the unity of mental concepts. How can I understand others as minded in the very same sense in which I understand myself as minded? Clearly, Merleau-Ponty's recurring claim to the effect that I can understand other bodies as minded because I experience myself as embodied effectively addresses that problem. There is no fundamental problem about extending the very same concept of, say, anger to others, if the anger I experience in myself has an observable, bodily aspect to it. I may not ascribe anger to myself on the basis of my visible and audible behaviour - although in some cases I might - whereas I standardly do so in the case of others. But if the concept of anger is the concept of something that typically has both outwardly visible components, and 'inner', subjective ones, then there seems to be no mystery about how it can be the same concept that we apply in these two cases. In my own case, I typically - though not necessarily always - apply the concept on the basis of a certain 'inner' feeling, let us say. In the case of others, I typically apply it on the basis of outward behaviour. But the concept I

\footnotetext{
${ }^{11}$ Though obviously, it may be far from evident what the other person makes of the scene he or she is looking at.
} 
apply in either case is the concept of something that typically has both types of component: outward behaviour and 'inner' feeling.

Although much more could be said about these matters, that is all I will say about the conceptual problem. ${ }^{12}$ I want to spend a little more time on the epistemological problem, since I don't think Merleau-Ponty's insistence on the embodiment of the mental plays quite as straightforward a role in dealing with that problem as it does with respect to the conceptual problem. ${ }^{13}$

The epistemological problem is the problem of how we can know what another thinks or feels (or how our beliefs about these things can be rationally justified). Merleau-Ponty's writings strongly suggest a perceptual account of our knowledge of other minds. ${ }^{14}$ That is, under favourable circumstances I see that another person is seeing, and that is how I know that he sees (cf. above). Or again, 'I perceive the other's grief or anger in his behaviour, on his face and in his hands' (2012, 372); that is how I know that the person is grieving or angry. For Merleau-Ponty, as we have seen, this has everything to do with embodiment. I can have such perceptual knowledge of another's grief or anger, he thinks, 'because grief and anger are variations of being in the world, undivided between body and consciousness' (ibid.). ${ }^{15}$

\footnotetext{
${ }^{12}$ See Smith (2010a) for some worries about whether embodiment can help to solve the conceptual problem of other minds.

${ }^{13}$ In the following, I concentrate on the 'what' version of the epistemological problem.

${ }^{14}$ The same goes for Scheler (1954, Part III). Although Husserl's position is somewhat ambiguous, it has been read as offering a perceptual account (Smith 2010b). Outside the phenomenological tradition, Wittgenstein, Austin, and McDowell, among others, have defended perceptual accounts.

${ }^{15}$ When defending a perceptual account of our knowledge of others' mental states, Merleau-Ponty usually picks emotions as relevant examples (see e.g. 1964b, 52, where the examples are anger and fear, and 2008, 63-64, where the example is anger). I think this is a wise choice. Emotions have characteristic facial and bodily signatures in a way e.g.
} 
But precisely what role does the embodiment of emotion play in securing a perceptual account of our knowledge of other people's emotions? In attempting to answer this question, I will need to go beyond what little Merleau-Ponty says that specifically addresses the epistemological problem. So I cannot confidently say that what follows is a Merleau-Pontian take on the problem, although I believe it constitutes one particularly promising way of filling in some of the details that seem lacking in his scattered remarks on the topic (cf. Overgaard 2012).

To see how embodiment might be important in the context of the epistemological question, consider first an argument to the effect that embodiment plays no important role at all. Fred Dretske has argued that we might be able to see (and on that basis know) that another is angry even if we cannot see her anger as such (Dretske 1973). To think otherwise, he argues, is to commit a fallacy. It is the same fallacy we commit if we think that just because we cannot see wind (moving air), we cannot see that it is windy either. Why is this a fallacy? Because first of all, it seems plausible that we cannot see (clean) air - clean air is transparent. If in some cases we may be said to see some body of air, what we actually see will be dust particles and the like in the air. If we cannot see air, then we cannot see moving air either. That is, we cannot see wind. Nevertheless, it seems obvious that we can see that it is windy, for example by seeing leaves whirling around. So clearly it is wrong to think that we need to be able to see the wind (i.e., the moving air) itself in order to see that it is windy. I think we can accept Dretske's point about wind here, as well as the general point that we must not think that it is a necessary condition on seeing that some object has a particular feature or property that we are able to see that feature or property itself.

beliefs and desires surely do not. Thus, it is much more plausible that we might have perceptual knowledge of the former than of the latter. 
If emotions are embodied, they - or at least their outward, bodily aspects - are the sorts of things we might literally see ${ }^{16}$ just as we literally see tables, apples, and facial contortions. If emotions have no outward aspects, we cannot see them in this way, but this does not mean that our knowledge of other people's emotions cannot then be perceptual, Dretske thinks. On his account, I see (and am thereby in a position to know) that Maurice is angry provided the following conditions are met:

\section{Primary Epistemic Seeing (PES):}

(i) Maurice is angry; (ii) I see Maurice; (iii) the conditions under which I see Maurice are such that he would not look the way he now looks to me unless he was angry; and (iv), believing the conditions are as described in (iii), I take Maurice to be angry (see Dretske 1969, 79-88, 183-190; cf. Cassam 2007, 163).

Primary epistemic seeing, Dretske argues, yields non-inferential - i.e. perceptual - knowledge. If Dretske is right, perceptual knowledge of other people's emotions requires that other people be straightforwardly perceptible; but it does not require that their emotions be straightforwardly perceptible. And so, to the extent that conditions (i)-(iv) can be met, it seems we can have perceptual knowledge of others' emotions regardless of whether emotions are embodied or not. Will McNeill (2012a) has argued that things are not that simple, however. To see why not, we first need to introduce Dretske's notion of 'secondary epistemic seeing'. This is a kind of seeing in which condition (ii) is not met. That is to say, you don't see Maurice himself, but some

\footnotetext{
${ }^{16}$ When I speak of 'straightforwardly' or 'literally' seeing some object, event or property, I have in mind Dretske's notion of 'non-epistemic' or 'simple' seeing (Dretske 1969, ch. 2).
} 
other object or objects - say, the broken crockery strewn across the floor of his flat. Seeing this will permit you to see - secondarily - that Maurice is angry provided the following conditions are met:

\section{Secondary Epistemic Seeing (SES)}

(i) Maurice is angry; (ii) you see the crockery and see (primarily) that the crockery is broken; (iii) conditions are such that the crockery would not be broken unless Maurice were angry; and (iv) believing conditions to be as described in (iii), you take Maurice to be angry (cf. Dretske 1969, 153)

Importantly, secondary epistemic seeing yields only inferential knowledge, not perceptual knowledge. There is an epistemic 'gap' between your seeing the crockery and its being broken, and the claim that Maurice is angry. That gap must be filled by a justified belief that if the crockery is broken, then Maurice is angry. If you are completely oblivious about any connection between the broken crockery you see and Maurice's state of mind, then seeing that the crockery is broken gives you no basis for judging Maurice to be angry. The necessity of the connecting belief in this case makes your knowledge that Maurice is angry inferential.

McNeill (2012a, 2012b) maintains that the primary-secondary distinction turns not only on which objects you see, but also on which properties of objects that you see. His idea is that if you want non-inferential knowledge that Maurice is angry it is not sufficient that you see Maurice; you also need to see the relevant feature of Maurice, viz. his anger. To illustrate this point, McNeill contrasts the way a normally sighted person might see that the traffic light is glowing red with the way a colour-blind person might see the same. Both can see, in a primary way, that the traffic light is glowing red. But only the former person sees this by seeing the light's redness. The colour-blind person sees that the light is glowing red by seeing that the top light (which she knows to be the red 
light) is illuminated. So in the case of the colour-blind person, McNeill maintains, there is an epistemic gap that must be filled by some justified belief connecting top lights with red lights; and this yields only inferential knowledge that the light is glowing red.

Let us now apply these points to the case of knowing that Maurice is angry. If his anger or 'angryness' is something you cannot see, the case seems similar to that of the colour blind person vis-à-vis the red light. You might count as seeing that Maurice is angry, but that will be by virtue of seeing some other property of Maurice, distinct from his 'angriness' - say his furrowed brow - that you have reason to believe is connected with Maurice's being angry in much the same way as the broken crockery is in SES, condition (iii) above. This will, however, only yield inferential knowledge that Maurice is angry. ${ }^{17}$

If this is right, then a perceptual account of our knowledge of other people's mental states requires those states to be perceivable. If one conceives of them as embodied, then that requirement seems to be met. ${ }^{18}$ Thus, embodiment might be part of a solution to the epistemological problem because it permits us to think of some mental states of others as literally

\footnotetext{
${ }^{17}$ One might question whether McNeill's points apply in all cases of seeing that an object $o$ has a feature or property $F$. Consider so-called 'kind properties', such as the property of being a traffic light. Once you have learned to recognize traffic lights, you will be able (in favourable circumstances) to see that something is a traffic light. But is the property of being a traffic light straightforwardly visible the way traffic lights themselves (and their colour properties) are? It is not clear what it would mean to say that it is. Yet we presumably do not want to say that we can only have inferential knowledge that something is a traffic light. So it seems as it cannot be a general constraint on non-inferential, perceptual knowledge that $o$ is $F$ that $F$ ness is straightforwardly visible. If so, it remains an open question whether your knowledge that Maurice is angry must be inferential, even if his anger is not straightforwardly visible. Still, absent a positive reason to think McNeill's points do not apply in the case of seeing mental features (e.g. being angry), the only way to secure a non-inferential account of our knowledge of other people's anger would be to show that another's anger can be straightforwardly seen. (I am indebted to Rasmus Thybo Jensen for raising these concerns.)

${ }^{18}$ See McNeill (2012b) and Overgaard (2014) for relevant discussion.
} 
visible (to the extent that their outward aspects are literally visible), which in turn allows for genuinely non-inferential PES of those states. Does embodiment also matter to the empirical problem of other minds? I argue in the next section that it does not.

\section{The Empirical Problem of Other Minds}

The empirical problem, unsurprisingly, is not exclusively or even primarily the business of philosophers. It is precisely an empirical problem - the problem of how people actually go about identifying the mental states of other people, what routines they may employ, what sub-personal mechanisms are involved. Such a problem is unlikely to be solved from the armchair. But that does not mean that philosophers have nothing to contribute to its solution. In particular, I will argue in this section that Merleau-Ponty has something important to say about what will not suffice to solve the problem. ${ }^{19}$

In the social cognition literature, a widespread assumption is that others' mental states are imperceptible or 'unobservable', and that this (supposed) fact constrains the possible shape of the solution to the empirical problem in important ways. More precisely, it is assumed that because the mental states of others are 'unobservable', we must infer them. Alan Leslie gives a clear formulation of this line of thought:

One of the most important powers of the human mind is to conceive of and think about itself and other minds. Because the mental states of others ... are completely hidden from the senses, they can only ever be inferred. (Leslie 1987, 139; see also Johnson 2000, 22)

\footnotetext{
${ }^{19}$ Again, I will ignore the 'that' version of this problem. See Merleau-Ponty (1964c, 117) for remarks that seem pertinent to that version.
} 
Opponents of this line of thought often assume that it is not only widely accepted, but even underpins the mainstream social cognition debates. The issue in those debates, so the assumption goes, is not whether we (invariably) infer the mental states of others, but the nature of the inferences involved. ${ }^{20}$ But, so the opponents claim, the whole thing is based on a faulty premise. The mental states of others are not 'completely hidden from the senses'; and since they are not - that is, since they can be given in sense-perception - we don't need to employ inferences to detect their presence.

Arguably, the main advocate of this alternative account of mental-state detection is Shaun Gallagher. ${ }^{21}$ Gallagher's perceptual account 'rejects ... the Cartesian idea that other minds are hidden away' (Gallagher 2008, 164). The mental states of others are 'normally and frequently apparent in their embodied and contextualized behaviors, including their vocalizations, gestures, facial expressions, eye gaze, and situated postures' (Gallagher 2012, 188); they are not hidden 'behind' such behaviours. According to Gallagher, once we think of others' mental states as embodied, we see that there is no role for inferences to play in typical cases of social cognition. As he puts it, "there is no puzzle to solve, no inference to make, since everything is just out there and obvious' $(2008,165)$. So, for example, if 'emotions are constituted by features that may include bodily expressions, behaviors, actions expression etc.', then 'it becomes very easy to say that we can perceive emotions in others' (Gallagher 2013, 3).

There can be little doubt that Merleau-Ponty would be opposed to Leslie's inferential picture of social cognition. As we have already seen, Merleau-Ponty believes that we may

\footnotetext{
${ }^{20}$ The two main paradigms in the social cognition debate go under the names of 'theory theory' and 'simulation theory'. For some scepticism regarding the claim that those paradigms are inherently committed to Leslie's inferential picture, see Overgaard and Michael (2015).

${ }^{21}$ But there are many others, including Krueger 2012, Ratcliffe 2007, Reddy 2008, and Zahavi 2011. I myself defended a view of this sort in Overgaard (2010).
} 
sometimes perceive the mental states of others. Thus, Gallagher is justified in enlisting MerleauPonty as a supporter of the sort of perspective on social cognition that Gallagher himself defends (Gallagher and Varga 2014, 186-7; Gallagher and Zahavi 2008, 184-5). However, it is crucial to see that Merleau-Ponty - in apparent contrast to Gallagher - rejects the following conditional: if we think of, say, emotions as embodied, then it follows that there is no role for inferences to play in standard cases of emotion recognition. ${ }^{22}$ On Merleau-Ponty's view, as I will now show, emotions can be as embodied as you like, and it could still be that we would need to infer their presence in others. As a matter of fact, we generally do not need to infer them, Merleau-Ponty thinks. But the fact that we do not need to infer them is not entailed by the fact that they are embodied.

Consider the following passage:

The [angry] gesture does not make me think of anger, it is the anger itself. And yet, the sense of the gesture is not perceived like, for example, the color of the rug. If it were presented to me as a thing, then it would not be clear why my understanding of gestures should be restricted, for the most part, to human gestures. ... I do not even understand emotions in primitive people, or in milieus too different from my own. ... The sense of the gestures is not given but rather understood, which is to say taken up by an act of the spectator. The entire difficulty is to conceive of this act properly and not to confuse it with an epistemic operation [opération de connaissance]. (MerleauPonty 2012, 190)

\footnotetext{
${ }^{22}$ Everyone accepts that inferences may be called for in situations in which people behave in odd and unpredictable ways.
} 
Merleau-Ponty makes several important points in this passage. First, even if the gesture is anger made visible, it does not follow that the emotional meaning of the gesture - that is, its being an angry gesture - is 'given' to one when one sees the gesture (and thus sees the other's anger). This point is actually a simple one, as we can see if we consider a complex physical object such as a bicycle. Presumably, there are people in the world who have never seen (or heard of) bicycles, let alone ridden them. It is safe to assume that, if presented with a bicycle, such people would have little idea what they were looking at. But obviously, that would not prevent them from seeing the bicycle. ${ }^{23}$ They would precisely be at a loss to say what that thing - the thing they saw - was. So even if something is perfectly visible, it clearly does not follow that the meaning or significance of that something (or the kind of thing it is) is visible in the same way.

So, even if emotions and other mental states are 'embodied' in observable behaviour, as Merleau-Ponty suggests many mental states are, all that follows is that those mental states can be seen (or felt or heard). That is to say, it only follows that we can see (feel, hear) what is in fact an aspect of someone else's mental state. But so far, that does not tell us anything about how we recognize what we see as another's mental state. To think that to the extent that emotions are embodied and thus straightforwardly perceivable, they will be given to a perceiver as the mental states they are is to commit a fallacy. It is like thinking that just because our bicycle-ignorant people can see bicycles, they can also, immediately and without any sort of inference, see that they are bicycles. But of course they cannot. ${ }^{24}$

\footnotetext{
${ }^{23}$ As Dretske writes, 'Ignorance of $X$ does not impair one's vision of $X$; if it did, total ignorance would be largely irreparable' $(1969,8)$.

${ }^{24}$ I am not suggesting that our experiences of other people (and their emotions and other mental states) and our experiences of physical objects such as bicycles are alike in all fundamental respects. I am only making the point that the fact that $x$ is straightforwardly perceptible does not entail that what $x$ is, its being (an) $x$, its sense or meaning, is also given perceptually.
} 
Merleau-Ponty clearly exposes this myth for what it is. Remember, he states that the angry gesture is the anger, and so he clearly rejects the thesis that anger is something imperceptible, hidden away inside a disembodied mind. And yet the meaning of the gesture is, as Merleau-Ponty says, 'not given but rather understood', and that means we still need an account of how we understand it. Importantly, nothing said so far rules out an inferential account of our understanding. Merleau-Ponty sees this clearly, for as the quote continues, 'the entire difficulty' is to give an account of our act of grasping that does not conceive of the latter as 'an epistemic operation'. If this is still a difficulty at this stage that is obviously because, for all Merleau-Ponty has said, it could still be the case that our relations to other people's anger were like the relation of the bicycleoblivious to bicycles: It could be that, even though we saw those emotions, we would still need inferences - perhaps implicit or unconscious inferences - to recognize them as the emotions they are. ${ }^{25}$ Thus, embracing the claim that emotions (and other mental states) are embodied gets us precisely nowhere in terms of rendering inferences redundant.

A nice question, which I do not have space to give the careful treatment it deserves, is how Merleau-Ponty proposes to resolve the difficulty of conceiving of the act of understanding in terms other than those of epistemic operations. Let me say a few things about the sort of answer he gives. Immediately after making the point about epistemic operations, Merleau-Ponty writes:

Communication or the understanding of gestures is achieved through the reciprocity between my intentions and the other person's gestures, and between my gestures and the intentions which can be read in the other person's behavior. Everything happens

\footnotetext{
${ }^{25}$ I repeat: Merleau-Ponty is clear that our situation vis-à-vis others' emotions is not like that. We generally do not need to infer that others are angry, etc.
} 
as if the other person's intention inhabited my body, or as if my intentions inhabited his body. $(2012,190-1)$

Several passages in 'The Child's Relations with Others' echo the passage just quoted from Phenomenology of Perception. 'I live in the facial expressions of the other, as I feel him living in mine' (1964c, 146), Merleau-Ponty writes. And again, 'It is this transfer of my intentions to the other's body and of his intentions to my own ... that makes possible the perception of others' (ibid., 118).

Carman suggests that Merleau-Ponty's point is corroborated by recent research into so-called 'mirror neurons' (Carman 2008, 138). Mirror neurons are neurons that are activated both when a subject - in the classical mirror neuron research, a Macaque monkey - performs a particular action, like grasping a banana with the hand, and when the subject watches someone else perform the same type of action. According to one interpretation, what such findings indicate is that we understand the actions of others using much of the same neurological machinery that we use in performing our own actions, only taking it 'off line', that is, using it in such a way that it does not issue in actual actions on our own part. We 'mirror' or 'simulate' the other's action in our brain. ${ }^{26}$ Perhaps Carman is right to read Merleau-Ponty as pointing in a similar direction. But it seems to me that the point just made about mirroring at best captures only half of what MerleauPonty is saying. He is not just saying that the other's intention 'inhabits my body', but also that my intentions inhabit his. This, moreover, is supposed to be something I experience. One way of reading Merleau-Ponty here is the following: not only do I experience the other's gestures as resonating with my own intentions (and emotions); I also feel that my own gestures resonate with

\footnotetext{
${ }^{26}$ See Goldman and Gallese (1998) for an early paper that explicitly links the discovery of mirror neurons to a 'simulation theory' of social cognition.
} 
something within the other. That is to say, the angry gesture that I see makes sense to me in terms of my own emotional repertoire; but I also feel the other make sense of my own angry gestures - I experience them as being understood, taken up somehow, by the other.

Much more needs to be said about this before we can have a solid enough grasp of Merleau-Ponty's proposal to begin to assess its possible merits. I leave this as a topic for another occasion. For present purposes, Merleau-Ponty's hints at a positive account of how we grasp the meaning of other people's gestures are important only to the extent that they underscore the conclusion I have already tried to establish: Merleau-Ponty evidently does not think that conceiving of emotions and other mental states as embodied means that "everything is just out there and obvious' ${ }^{27}$ On the contrary, we still need an account of how we understand those mental states as the mental states they are.

\section{Concluding remarks}

I have suggested that there is not one problem of other minds, but (at least) three kinds of problem: conceptual, epistemological, and empirical kinds. Moreover, I have suggested that Merleau-Ponty thinks embodiment ( $a$ ) solves, or perhaps dissolves, the first problem; $(b)$ provides an important element in a perception-based solution to the 'what' version of the second problem; while (c) not proffering a solution to the 'what' version of the third problem. Finally, I have argued that MerleauPonty is right about $(c){ }^{28}$

\footnotetext{
${ }^{27}$ Pace Gallagher, or so it seems. There may, however, be other ways of reading Gallagher here (see Overgaard 2015).

${ }^{28}$ I thank audiences at Rikkyo University, Tokyo, and Mary Immaculate College, Limerick, for helpful feedback on some of the material included here. I am particularly indebted to Andrew Inkpin and Jack Reynolds for their detailed comments on the penultimate draft of the paper.
} 


\section{Bibiliography}

Austin, J. L. (1979). Philosophical Papers, ed. J. O. Urmson and G. J. Warnock. Oxford: Oxford University Press. Avramides, A. (2001). Other Minds. London: Routledge.

Carman, T. (2008). Merleau-Ponty. London: Routledge.

Cassam, Q. (2007), The Possibility of Knowledge. Oxford: Clarendon Press.

Dretske, F. (1969). Seeing and Knowing. London: Routledge \& Kegan Paul.

Dretske, F. (1973). Perception and other minds. Noûs 7: 34-44.

Gallagher, S. (2008). Inference or interaction: social cognition without precursors. Philosophical Explorations, 11, 163174.

Gallagher, S. (2012). In defense of phenomenological approaches to social cognition: Interacting with the critics. Review of Philosophy and Psychology 3: 187-212.

Gallagher, S. (2013). A Pattern Theory of Self. Frontiers in Human Neuroscience 7: Article 443.

Gallagher, S. and Varga, S. (2014). Social Constraints on the Direct Perception of Emotions and Intentions. Topoi 33: 185-199.

Gallagher, S. and Zahavi, D. (2008). The Phenomenological Mind. London: Routledge.

Gallese, V. \& Goldman, A. (1998). Mirror Neurons and the Simulation Theory of Mind-Reading. Trends in Cognitive Sciences 2: 493-501.

Goldman, A. I. (2006), Simulating Minds. New York: Oxford University Press.

Goldman, A. I. (2012) Theory of mind. In E. Margolis, R. Samuels, and S. P. Stich (eds.), The Oxford Handbook Johnson, S. (2000). The recognition of mentalistic agents in infancy. Trends in Cognitive Sciences 4: 22-28.

Gomes, A. (2011). Is There a Problem of Other Minds? Proceedings of the Aristotelian Society 111: 353-373.

Hyslop, A. (2010). Other Minds. In E. N. Zalta (ed.), The Stanford Encyclopedia of Philosophy (Fall 2010 Edition). $\mathrm{URL}=<$ http://plato.stanford.edu/archives/fall2010/entries/other-minds/>

Krueger, J. (2012). Seeing mind in action. Phenomenology and the Cognitive Sciences 11: 149-173.

Leslie, A. M. (1987). Children's understanding of the mental world. In R. L. Gregory (ed.), The Oxford Companion to the Mind (pp.139-142). Oxford: Oxford University Press.

McNeill, W. E. S. (2012a).On Seeing that Someone Is Angry, European Journal of Philosophy 20: 575-597.

McNeill. W. E. S. (2012b). Embodiment and the perceptual hypothesis. The Philosophical Quarterly 62: 569-591.

Merleau-Ponty, M. (1963). The Structure of Behavior, trans. A. L. Fisher. Pittsburgh: Duquesne University Press. 
Merleau-Ponty, M. (1964a), Signs, trans. R. C. McCleary (Evanston: Northwestern University Press).

Merleau-Ponty, M. (1964b). Sense and Non-Sense, trans. H. L. Dreyfus and P. A. Dreyfus. Evanston: Northwestern University Press.

Merleau-Ponty, M. (1964c). The Primacy of Perception and Other Essays, ed. J. M. Edie, trans. J. M. Edie et al. Evanston, IL: Northwestern University Press.

Merleau-Ponty, M. (2008). The World of Perception, trans. O. Davis. London: Routledge.

Merleau-Ponty, M. (2012). Phenomenology of Perception, trans. D. Landes. London: Routledge.

Nagel, T. (1986), The View from Nowhere. New York: Oxford University Press.

Nichols, S. and Stich, S. (2003). Mindreading. Oxford: Oxford University Press.

Overgaard, S. (2010). The Problem of Other Minds. In S. Gallagher and D. Schmicking (eds.), Handbook of Phenomenology and Cognitive Science. Dordrecht: Springer, 254-268.

Overgaard, S. (2012). Other People. In D. Zahavi (ed.), The Oxford Handbook of Contemporary Phenomenology. Oxford: Oxford University Press, 460-479.

Overgaard, S. (2014). McNeill on Embodied Perception Theory. The Philosophical Quarterly 64: 135-143.

Overgaard, S. (2015). The Unobservability Thesis. Synthese (Online First). DOI: 10.1007/s11229-015-0804-3

Overgaard, S. and Michael, J. (2015). The Interactive Turn in Social Cognition Research: A Critique. Philosophical Psychology 28: 160-183.

Pickard, H. (2003). Emotions and the Problem of Other Minds. In A. Hatimoysis (ed.), Philosophy and the Emotions. Cambridge: Cambridge University Press, 87-103.

Ratcliffe, M. (2007). Rethinking Commonsense Psychology. Basingstoke: Palgrave Macmillan.

Reddy, V. (2008). How Infants Know Minds. Cambridge, MA: Harvard University Press.

Russell, M. and Reynolds, J (2011). Transcendental Arguments About Other Minds and Intersubjectivity. Philosophy Compass 6: 300-311.

Scheler, M. (1954). The Nature of Sympathy, trans. P. Heath. London: Routledge \& Kegan Paul.

Smith, J. (2010a). The Conceptual Problem of Other Bodies. Proceedings of the Aristotelian Society 110: 201-217.

Smith, J. (2010b), Seeing Other People. Philosophy and Phenomenological Research 81: 731-748.

Wisdom, J. (1968) Other Minds. Berkeley: University of California Press.

Wittgenstein, L. (1958). The Blue and Brown Books. Ed. R. Rhees. Oxford: Blackwell. 
In Continental Philosophy Review 50 (2017): 65-80. Published version freely available at: http://rdcu.be/IF27

Zahavi, D. (2011). Empathy and direct social perception: a phenomenological proposal. Review of Philosophy and Psychology 2: 541-558 